\title{
How much are we aware of harmful effect of tattoo to health? an exploratory research in Kolkata
}

\begin{abstract}
For over a last few decades, tattoo is gaining lots of attention especially in the field of body modification within the younger generation in our society. But generally the most important aspect is overlooked while having a tattoo, i.e. the health risks and the awareness related to tattoo. Researchers have stated that many diseases can be transmitted through tattooing if proper hygiene is not maintained. The present study has been carried on, in the metropolitan city Kolkata of West Bengal which seeks to understand the present awareness scenario regarding tattoo in India. A qualitative study using in-depth interview is performed with the individuals including tattoo artists and tattoo owners from two tattoo studios. The study suggests that no proper legal certification of tattoo artist and tattoo parlors in India. In most cases low quality of ink were used and no proper sterilization was there. Unaware of such factors people having craved for getting a cheap tattoo results health risk.
\end{abstract}

Keywords: tattoo, health risk, hygiene, awareness, legal, tattoo machine, health awareness, health risks
Volume I Issue I - 2017

\author{
Archita Dey,' Kaustav Das, ${ }^{2}$ Koel \\ Mukherjee, ${ }^{3}$ Sutapa Mukhopadhyay ${ }^{4}$ \\ 'Department of Anthropology, North East Regional Centre, \\ India \\ ${ }^{2}$ Department of Anthropology, Narasinha Dutt College, India \\ ${ }^{3}$ Department of Anthropology, Haldia Govt. College, India \\ ${ }^{4}$ Department of Anthropology, University of Calcutta, India
}

Correspondence: Kaustav Das, Guest Lecturer, Department of Anthropology, Narasinha Dutt College, 129 Belilious Road, Howrah-7II I0I, India, Tel +9I $9874583159,+9187776$ 92189,033-2512 1211, Email kaustavanthro@gmail.com

Received: May 29, 2017 | Published: June 30, 2017

\section{Introduction}

Tattoo a newly emerging type of body modification that has been increased in popularity recently needs no introduction. We often notice several people having tattoo in our day to day life. Stirn et al. ${ }^{1}$ noted how individuals utilized body modification for specific body sensations, as well as how they experienced and felt about their bodies before and after modification. Mostly hearing the word tattoo the first thing that comes to mind is the process of having a permanent tattoo i.e. by inserting ink beneath the skin, so the question that would commonly come after knowing this is if tattoo is harmful to health or not. So, the answer of this question is probably a difficult one. Some tattooing cultures may not be able to utilize historical application methods, as sterilization techniques may not work well on traditional implements. ${ }^{2}$ Studies have shown that people may get motivated for tattoos because of the risk to develop their own policies. ${ }^{3}$ Body modification can be viewed as a complex behavior for all the elements included in the entire process. Certainly, there can be both physical and emotional elements for an individual's internalized choice to get a tattoo or piercing.

Health risks involved with obtaining tattoos could be considered within an embedded health behaviors context. Despite the potential unknown effects of some tattoo ink ingredients, no studies have linked tattoos with skin cancer. ${ }^{4}$ Doremus ${ }^{4}$ also noted that tattoos can make it more difficult to detect skin cancer or can cause incorrect identifications of cancer in lymph node. Blood-borne pathogens like Hepatitis B and C can be transmitted through tattooing., ${ }^{5,3}$ This fact once led to a historic deferral of recently tattooed potential blood donors. ${ }^{6}$ Cegolon et al. ${ }^{7}$ offered that health care professionals, secondary school staff, and higher education staff could broadcast information about body modification risks and implications, as young people continue to procure it. To have a tattoo one must maintain the proper hygiene, if not then the tattoo could turn as a biggest mistake of one's life. One having the tattoo and the tattoo artist both have to be aware of the consequences of the tattoo. So, the most important and the needed thing in tattoo is the awareness.

\section{Methodology}

The interest of this research lies in uncovering the present scenario of health risks and awareness about tattoo in Kolkata. For dipper understanding, primary data were collected through open-ended as well as in-depth interviews on a small number of respondents who were getting tattoo or who came for removal from two local tattoo studios along with tattoo artists for over a period of one month to explore their perspectives on the issue concerned.

\section{Results and discussion}

When it comes to awareness regarding tattoo, participants have often said that awareness in the context of tattoo is very less in India. Tattoo artists said that most of the tattoo studios doesn't maintain minimum hygiene and use very low quality ink, to make the tattoo cheaper. They also said that client should also be more aware of it, as tattoo is something permanent, and it's done on the skin, therefore finding a cheaper option is not something make sense.

\section{Legal awareness}

Participants are found to be said that there are no legal rules in India, for tattooing and they think that this is the reason of people having bad tattoos. Participants are found those who have no knowledge about tattoo and had learned it from you tube, and started tattooing. Participants have, mostly tattoo artist have said if there is a legal certification of tattooing in India then this cheap tattoo parlors wouldn't have been aroused.

I. Soheli, a tattoo artist, describes about the certification of the tattoo studio, and how cheap inks are bought from China, to do cheap tattoos.

"This is also a legal issue, maximum of the tattoo parlor is not certified, they are arranging a machine and started doing it, and it's not that easy. If legally and rules are made about certification, then you can see that more than half tattoo artist and parlors are removed from Kolkata rather you could say India. If you go to Esplanade, then 
you can there are many tattoo artists in shoe shop. At a side, they are selling shoes and parallaly they are doing tattoo. Maximum of our removal customer comes from Mani Square and Esplanade. Even this happened that one has done the tattoo at 3.00 PM and came to remove it here at 4:30. They use so bad colour that after doing it there are rashes and itching. There are no such things like certifications. They are learning from someone then buying machines from China or Bangkok, they are getting the full set machine plus color within 14000 to 15000 rupees, whereas if you got to buy the same set from USA or UK it will cost of around 2 or 3 lakhs. They just do it for a cheap price and they don't bother after that what happens to you for that.'

II. Bitan, another tattoo artist, describes the importance of making it a legal issue of not having tattoo until 18 . As till 18 our body gets though some hormonal changes, therefore having a tattoo before 18 , could make things worse.

"Legal point is there another biological point is there, before 18 . I mean for a guy 20 till 21 the modification or the changes of hormonal and for the ladies it almost done within the 18. So, for girls I keep it on like 18 and even for guys if they do it on hand or something that doesn't effect. So, till 21 there is no major hormonal change its nominal, so 18 is the minimum bar I used to keep for the legal as well as the biological, but till time here in Kolkata or here in India there is no such rule as legal point. I mean people are going everywhere 15/16 these kids they are getting the tattoo done. There is no government rule on this tattoo yet... but outside of our country it's off course there. Whenever you are making a tattoo you are soulful responsible to your client and that should be. In here the story is different, after having a tattoo they got the money and forget, all they see this as a business, but you must make a rapport with the client, but what I have experienced I have more than like $3 / 4$ thousand of friends like now and out of like 3 thousand 2 thousand are my clients. Once I have dig the person with needle and ink, he became a lifelong friend of mine."

\section{Health awareness}

Tattoo is something that is done into the skin, therefore if hygiene is not maintained then could spread disease or contamination. Beside this if a person has no proper tattoo education then it could also affect the person who is getting tattoo. In India, there no such professional courses about tattoo, but now some studios provide their own courses, and also provide a certificate after completing it. Many of the cases are heard from the tattoo artist those who doesn't maintain the basic hygiene like wearing a glove. Neel Das has shared a picture with us that shows the completely how much there is lack of awareness related with tattooing in our society (Figure 1).

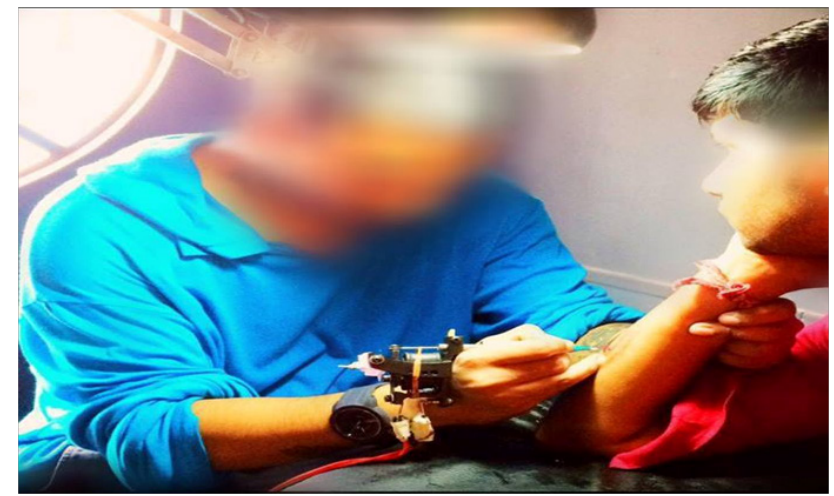

Figure I The lack of awareness about tattoo within tattoo artist, who even doesn't use gloves to cover their hand to avoid contamination.
A. Bitan said that tattooing is increased very recently, and he thinks that one day there will be everyone having a tattoo. So, he said how he sterilizes all equipment of his studio and he thinks that the tattoo artist should be more aware of the basic hygiene.

"Nowadays the way tattoo is increasing one day will come when everyone will have a tattoo... so tattooist should be more aware, just for money using cheap colour or needles is not good... Now see these tube (showing the two-tube light in the room where he is doing the tattoo), this one tubes are of Rs. 7,500. These sterilize this room. Every day before starting to work, it should be run for $3 \mathrm{~min}$ and after completing your work. This is to sterilize the place. Because there are many things, you can't sterilize by hand, so this is the best way."

B. A tattoo artist (not disclosing the identity here), who is not even 18 now and had learn about tattoo from internet, seeing video on YouTube, said proudly that he had done many bad tattoos, as he doesn't even know how to run the machine and all, and he thinks that it's okay to have to bad works to learn something good.

"When I came here I wanted to income I never thought of tattoo that time, but I thought ok will I get sufficient money only by drawing? So, that time I meet a person to do a tattoo. I wanted to do a tattoo for style. So, I meet with him and done my first tattoo and when I went to him I saw that there is a good income in this field. So, I said my father to buy me a tattoo machine and as usual he denied, so after a lot of trying I successfully convinced him and my father bought me that machine. So, after buying the machine I started trying it up on my own body I did on my legs first then one on my hands. Then I started to do it on my friends. Very first I faced some problems as there was no one from whom I can learn it. So, who helped to learn this is you tube."

C. Soheli from Bitz studio has come to the last stage of tattoo education, where she said she has to give exam online from here, and she is doing the course from the organization namely American World Wide Tattoo, and after giving the exam, she will provide a certificate online by which she can make her own tattoo studio at any corner of the earth.

"Yes, from here only. After learning from here you will be certified to. I am under American World Wide Tattoo. After completing my course, I will give exam online, then if I pass they will send me certificate online. With that certificate, I can open my tattoo parlor at any corner of the earth. In India, we don't need all this, if we go outside India they will ask for your certificate. They treat health first rather than money."

\section{Conclusion}

This study shows the present scenario of the tattoo awareness in Kolkata, as there is a very lack of awareness in case of tattoos; therefore the risk of regrets also gets increased. As there are several tattoo artists who don't care about the quality of the product or about maintaining hygiene for making their business successful, and to earn more money by providing cheap tattoos. People are less aware about their health until and unless they have gone through some issues that made them regret for their tattoos. Tattoo can cause several contaminations and infection to the skin, if not done properly. In fact, in India where tattoo is practiced dominantly nowadays, has no certain rules about this, not even certification of tattoo artists, thus anyone is picking up the machine and starting to do a tattoo, without even having knowledge and training about it completely. Therefore, 
this study strongly recommends the need of tattoo awareness and as well as tattoo education in India. And further study also needed with larger samples before going to formulate any strategy.

\section{Acknowledgements}

None.

\section{Conflict of interest}

The author declares no conflict of interest.

\section{References}

1. Stirn A, Hinz A. Tattoos, body piercings, and self-injury: Is there a connection? Investigations on a core group of participants practicing body modification. Psychother Res. 2008;18(3):326-333.
2. Martí J. Tattoo, cultural heritage, and globalization. Scientific Journal of Humanistic Studies. 2010;2(3):1-9.

3. Miller VG. Body art and the primary care provider's responsibilities. Texas Public Health Journal. 2010;62(2):22-26.

4. Doremus AR. Can tattoos cause cancer? Clinical Journal of Oncology Nursing. 2009;13(2):231-232.

5. Selekman J. A new era of body decoration: What are kids doing to their bodies? Pediatric Nursing. 2003;29(1):77.

6. Menitove JE. Accepting donors with tattoos and other in-favor changes. Transfusion. 2009;49(4):615-616.

7. Cegolon L, Miatto E, Bortolotto M, et al. Body piercing and tattoo: Awareness of health related risks among 4,277 Italian secondary school adolescents. BMC Public Health. 2010;10:73-80. 